\title{
How Do the Chinese Make Love? A Community Based Survey in China
}

\author{
Xin Tao, Jun Chen*, Bin Zhang*, Erhong Zhang, Tao Qi, Mingzhu Cao \\ Department of Infertility and Sexual Medicine, The Third Affiliated Hospital of Sun Yat-Sen University, \\ Guangzhou, China \\ Email: ${ }^{*}$ ichen121121@hotmail.com, ${ }^{*}$ doc305@163.com
}

Received 28 February 2014; revised 1 April 2014; accepted 10 April 2014

Copyright $@ 2014$ by authors and Scientific Research Publishing Inc.

This work is licensed under the Creative Commons Attribution International License (CC BY).

http://creativecommons.org/licenses/by/4.0/

(c) (i) Open Access

\begin{abstract}
Aims: To investigate how the Chinese make love. Methods: From Jan. 2009 to Dec. 2009, a survey was carried out of 600 adults ( 300 male and 300 female adults) in Tianhe community (Guangzhou, China). Information included masturbation, sexual foreplay, oral sex, intercourse, coordination with sexual partner, self-evaluation of one's sexual function. Results: 255 females and 229 males fulfilled the questionnaires. $48.8 \%$ females and $68.7 \%$ males admitted of masturbation experiences. $59.9 \%$ women reported some passionate touch before sex, and $63.2 \%$ men reported some moderate touch. One third of the women could accept oral intercourse, while two thirds of the men couldn't accept oral intercourse. The frequency of sexual intercourse per month is less than 10 times in $72.5 \%$ women and $77.7 \%$ men. $72.9 \%$ men and $54.9 \%$ women would like to frequently change the position in sexual intercourse. Still, $72.9 \%$ men and $54.9 \%$ women would like to coordinate with the sexual partner when she/he had sexual requirement. $74.1 \%$ women thought her sexual function as general level. Conclusions: The results of the present study indicated that most men and women in China could enjoy their sex lives through the most common way: sexual intercourse. Although masturbation and oral sex are two of the common sex activities, part of the adults still had a negative attitude towards the two activities, especially women.
\end{abstract}

\section{Keywords}

Make Love, Sexual Foreplay, Sexual Intercourse, Oral Sex, Masturbation, Chinese

\section{Introduction}

Recently, the sexual attitude, knowledge and behavior in China had been more and more attentioned by experts.

"Corresponding author. 
It was found that the attitudes toward sexuality in China, since ancient time, a patriarchal society, were negative and repressive, and sexual behavior was restricted and forbidden outside of wedlock, and it was viewed as having a solely reproductive role [1]-[5]. And it was also found the sexual beliefs and practices of Chinese had been more and more influenced by western liberally sexual belief [6]-[12].

However, the area of how the Chinese make love, the most essential elements of sex, had seldom been investigated, which lead to knowledge gaps in this area in China. The aim of the present research is to focus on the area which is seldom attentioned in China and to preliminarily clarify the difference of attitude and experience of making love between the two genders in Tianhe community (Guangzhou, China), in the field of masturbation, sexual foreplay, oral sex, sexual intercourse and coordination with sexual partner, self-evaluation of sexual function.

\section{Method}

\subsection{Setting and Population}

In Tianhe community (Guangzhou, China), a random sampled survey of the Chinese how to make love was carried out from Jan. 2009 to Dec. 2009. The information related to sociodemographics, health status was also included in this study.

To be eligible for this study, a person needed to meet the following criteria: (1) be a member of the randomly selected households; (2) have sexual experience; (3) be competent to provide signed informed consent. Exclusion criteria were: (1) use of any antidepressant or other medications known to affect sexual function, (3) diabetes, heart disease, or thyroid disease, etc, which may affect sexual function.

A total of 300 female and 300 male adults in Tianhe community (Guangzhou, China) were investigated. Among those, 255 female (mean age was 28.6 years old, range 20 - 48 years old) and 229 male adults (mean age was 31.8 years old, range 18 - 54 years old) completed the whole interview conducted by trained clinical doctoral students and nurses, yielding a finale response rate of $85.0 \%$ for female and $76.3 \%$ for male. All data were obtained during this 2-h, face-to-face interview.

\subsection{Questionnaire Contents}

A questionnaire was developed, based on the objectives of the study. The questionnaire was refined through pilot testing and cognitive interview. No names were included in the answer sheets to ensure confidentiality. The questionnaire contained questions in the following areas: (1) background and demographics; (2) masturbation; (3) sexual foreplay; (4) oral sex; (5) intercourse; (6) Coordination with sexual partner; (7) self-evaluation of sexual function.

\subsection{Survey Implementation}

The interview was taken alone in a private room or in a situation with less apparent privacy, generally in the participant's home. Prior to fulfilling the questionnaire, the interviewers demonstrated that the personal information on the questionnaires neither be disclosed nor publicized. After respondents completing a paper, snacks, soft drinks were offered as incentives for participation.

\subsection{Statistical Analysis}

Descriptive statistics included means and standard deviations for continuous variables and percentages for categorical variables. Categorical variables were compared using Pearson Chi square, and Fisher exact tests as appropriate. All tests were two tailed, and a $P$ value less than 0.05 was considered significant. Analyses were performed using SPSS version 13.0.

\section{Results}

Questionnaires of 45 female and 71 male participants were incomplete. The reasons were mainly: (1) lack of time; (2) too many missing answers; and (3) reasons unknown.

Demographic characteristics of the sample were presented in Table 1. Race/ethnicity was also collected in this study, and all of the participants were Han Nationality. 
Table 1. Demographic characteristics of the sample.

\begin{tabular}{|c|c|c|}
\hline & Female & Male \\
\hline Sample size $(n)$ & 255 & 229 \\
\hline Age (mean age) & $20-48(28.6)$ & $18-54(31.8)$ \\
\hline \multicolumn{3}{|l|}{ Occupation } \\
\hline Worker & $30(11.76 \%)$ & $23(10.04 \%)$ \\
\hline Farmer & $43(16.86 \%)$ & 25 (10.92\%) \\
\hline Technician & 65 (25.49\%) & $73(31.88 \%)$ \\
\hline Businessman & $36(14.12 \%)$ & 39 (17.03\%) \\
\hline Jobless & $23(9.02 \%)$ & $18(7.86 \%)$ \\
\hline Others & 58 (22.75\%) & $51(22.27 \%)$ \\
\hline \multicolumn{3}{|l|}{ Education level } \\
\hline Higher (college or higher education ) & $100(39.22 \%)$ & $132(57.64 \%)$ \\
\hline Lower (primary or middle schools education) & $155(60.78 \%)$ & 97 (42.36\%) \\
\hline \multicolumn{3}{|l|}{ Marital status } \\
\hline Married & 235 (92.16\%) & $201(87.77 \%)$ \\
\hline Single & $17(6.67 \%)$ & 28 (12.22\%) \\
\hline Divorced & $3(1.18 \%)$ & $0(0 \%)$ \\
\hline Lose spouse & $0(0 \%)$ & $0(0 \%)$ \\
\hline \multicolumn{3}{|l|}{ Menopausal status (for female only) } \\
\hline Pre- & 253 (92.2\%) & \\
\hline Peri- & $2(7.8 \%)$ & \\
\hline Post- & $0(0 \%)$ & \\
\hline
\end{tabular}

\subsection{Masturbation}

48.8\% female adult admitted having masturbation behaviors, while more than $68.7 \%$ male adult admitted, a significant difference was showed $(P<0.001)$. 54.9\% female adults who received primary or middle schools education and similarly, $48.2 \%$ female adults who received college or higher education have the behavior of masturbation, no significant difference was found. $68.3 \%$ male adults who received only primary or middle schools education, and $70.7 \%$ male adults who received college or above education have the behavior of masturbation. There is no significant variation was found $(P=0.731)$.

\subsection{Sexual Foreplay}

A passionate foreplay was defined as an "easily moved by the sexual desire, and steadily hold the emotional zeal during the foreplay before sex, for example, having your genitals caressed by your partner, kissing of sensitive areas of the body, breast petting while your are nude, etc."; a moderate foreplay as an "easily moved by the sexual desire, but the foreplay was limited in scope or effect, for example, breast petting while your are clothed, erotic embrace while dressed"; and a passive foreplay as an "have some extend of sexual desire, but lack in energy or will, and only accept foreplay passively".

More than 59.9\% women reported some passionate foreplay before sexual intercourse, while $26.1 \%$ male adults want passionate foreplay. $31.4 \%$ female and $63.2 \%$ men reported some moderate foreplay to get involved in sexual intercourse. $8.7 \%$ female adults and $10.7 \%$ male adult want passive foreplay respectively. There is significant difference demonstrated in their eager for foreplay $(P<0.001)$.

Female adults with higher education reported to require more passionate foreplay and less passive foreplay than those who received lower education $(70.0 \%$ vs $53.5 \%$; $3.0 \%$ vs $9.0 \% ; P=0.043)$. However, the same trend can't be found in male adults ( $25.0 \%$ vs $27.8 \%$; $10.6 \%$ vs $10.3 \%$; $P=0.886$ ). 


\subsection{Oral Sex}

The percentage of female adults who could accept oral sex, either gets it passively or do it actively, is much lower than the percentage of their male counterparts (33.33\% vs $61.1 \%, P<0.001$ ).

No correlation between education and their attitude of oral sex was observed in this survey. Among the female adults, 35.5\% ones with lower education and 33.3\% ones with higher education may do oral sex in their lives $(P=0.726)$. Similarly, $62.9 \%$ ones with lower education and $59.8 \%$ ones with higher education took oral sex as part of their sexual intercourse.

\subsection{Intercourse}

The frequency of sexual intercourse was divided into two groups, less than 10 times per month and at least 10 times per month. The survey reported $72.5 \%$ female and $77.7 \%$ male adults' sexual intercourse frequency is below 10 times per month, and no statistically significant difference of the frequency of their sexual lives between the male and female population $(P=0.208)$.

Although there were no significant variations among male and female adults by specialty, respondents with higher education more likely to have sexual intercourse less than 10 times per month than their counterparts with lower education (female: $71.0 \%$ vs $73.5 \%, \mathrm{P}=0.528$; male: $76.5 \%$ vs $79.4 \%, P=0.360$ ).

Regarding the conversion of sexual position, it was more common among male adults than female adults (87.8\% vs 76.9\%; $P=0.003$ ). Similar to the report of the frequency of sexual life, although there were no significant variations among male and female adults by specialty, respondents with higher education more likely to be fond of converting position than their counterparts with lower education (female: $81.0 \%$ vs $74.2 \%, P=0.232$; male: $90.9 \%$ vs $83.5 \%, P=0.062)$.

\subsection{Coordination with the Sexual Partner}

Much more male adults than female adults could coordinate with their sexual partner $(72.9 \%$ vs $54.9 \%$; $P<$ 0.001) when their partner require for sex.

A little more than half of female adults with high education and lower education could coordinate with their sexual partner (58.0\% vs 52.9\%, $P=0.528$ ). Approximately seven in ten male adults either higher education or lower education could coordinate with their sexual partner $(75.0 \%$ vs $70.1 \%, P=0.262)$.

\subsection{Self-Evaluation of Sexual Function}

17.3\% female adults felt self-confident of their sexual function, versus $39.7 \%$ male adults felt the same. $74.1 \%$ female adults took their sexual function as general level, but only $45.0 \%$ male adults were in this level. $8.6 \%$ female adults and $15.3 \%$ male adults thought their sexual function is not well and felt self-abase of it $(P<0.001)$.

Of the 100 female adults with higher education, $20.0 \%$ felt self-confident and $11.0 \%$ felt self-abasement of their sexual function, compared with $14.8 \%$ and $5.8 \%$ of the 155 female adults with relatively lower education $(P=0.151)$. Among the male adults, more people with higher education felt self-confident of their sexual function than the ones with lower education, and they were less self-abase of their sexual function (44.7\% vs 33.0\%; $9.9 \%$ vs 22.7\%; $P=0.037)$.

\section{Discussion}

This is the first report to systematically investigate Chinese how to make love. In this study, we found most men and women in Tianhe community (Guangzhou, China) could enjoy their sex lives through the most common way sexual intercourse. Men were more active than women in the leading position of sexual intercourse. Although masturbation and oral sex is one of the common sex activities, part of the adults still had negative attitude of these two activities, and especially for women.

\subsection{Masturbation}

From a public health perspective, masturbation is considered as a safe sexual activity. It has been promoted as a safe alternative to higher risk sexual practices by both researchers and clinicians [13]. It is a common sexual 
practice with significant variations in reporting between men and women [14]. In ancient China, masturbation was viewed as a cause for illnesses, and something unhygienic and ashamed. Part of the surveyors acknowledged masturbatory behavior, and the others influenced by the Confucian and Taoist sexual philosophy and the relatively conservative atmosphere, refused to present the truth.

In this survey, more men than women reported masturbatory behavior than women, and this tendency was also presented in other nations. The results of our survey was similar to the percentage of female and male's masturbation in US, which was 38\% women and $61 \%$ men reporting any masturbation over the preceding year [15]. While in England, 95\% men and 71.2\% women reported that they had masturbated at some point in their lives [14]. The similar rate was found in India [16], that nearly $60 \%$ of females and $94 \%$ of males have masturbated.

Female and male adults with different levels of education have nearly the same population with masturbation, while in Britain, a survey [14] reported masturbation increased with higher levels of education and social class, and these associations have been attributed to greater access to public debate, to information, and to sex education, which may help reduce fears and guilt, and thus increased willingness to report masturbation. It can be predicted that the relative conservative social opinion in China rather than the education level negatively influenced the attitude of people in China more. Besides, the masturbatory attitudes were positively correlated with masturbatory knowledge [17], while most Chinese were sexually illiterate, both female and male with lower as well as higher education having insufficient knowledge regarding masturbation, thus the correlation of masturbation with education can't be figure out.

\subsection{Foreplay}

The excitation and euphoria of the couple when they having sexual lives could affect each other, and thus encourage the partner. The facial expression, posture and tone could all be the approach that triggers sex pleasant sensation. Donnelly and Straus [18] indicated that because of traditional gender role socialization and higher levels of sexual activity in all areas (both fantasy and behavior), males are aroused at higher levels than women. The same situation appeared in this survey, more female adults than male adults need passionate foreplay to require a sexual arousal. Moreover, sexual conservative beliefs seem to be closely related to a certain extent to arousal difficulties in women, which seemed to be one reason that more females than males required for passionate foreplay. Another often-mentioned explanation for male-female differences in sexual foreplay focuses on biological differences between males and females. This argument posits that because the genetic and hormonal make-ups of males and females differ, it is possible that sexual foreplay and the subsequent sexual arousal were shaped by these influences.

\subsection{Oral Sex}

Oral sex is one common mode of sexual practices. Considering of anatomy, oral-genital sexual stimulation has the same sensitivity as the penis-vaginal intercourse or even more.

In this survey, we found that one third of the female adults and two thirds of the male adults can accept it. It suggested that sexual attitudes are more adoptive to the westernization, while sexual behavior are consistent with the historical or traditional culture, which is a well-known finding in social psychology studies that attitudes and behavior may be discordant [19]. Another interpretation might be that there is reluctance to report sexual dissatisfaction or sexual problems by women for any number of reasons-embarrassment or anxiety being two possibilities. Women generally felt more threatened than men when asked to report sensitive behavior [20]. On the other hand, men might have a motive to exaggerate their sexual behavior [21]. Therefore, they might be less likely to report the actual sexual behavior.

Another survey [22] in Jiangmen Guangdong Province reported that only 9.3\% of the couples had oral sex behavior. Several reasons account for these differences. First, Chinese are conservative in their sexual expression. Oral sex is part of the secret sexual lives, which they wouldn't acknowledge to others. Second, it represents a big gap between acceptance and practice of oral sex in Guangdong China. Besides, the receptivity didn't vary as the education level did. People in China, especially women, had long been influence by the traditional culture atmosphere, which considered "oral sex" as well as masturbation unhygienic and ashamed sexual activities. Thus they don't practice it often in their sexual lives even when some of them did accept this activity. 


\subsection{Intercourse}

Penis-vaginal intercourse is the most common way of sexual lives, because the genital responses of both sexes were strongest to intercourse [23]. In Wu Meiqiong's report [22], 98.6\% of the responders took vaginal intercourse as most frequent way. The frequency of intercourse is the most direct and most important demonstration of the quality of the couple's sexual lives. Yet, the frequency of intercourse can be affected by many factors [24], like demographic, familial, and social factors, etc. We found that $70 \%$ of the male and female adults had intercourse less than 10 times per month. And the results of our survey is similar to another report in America [25] which demonstrated that the average frequency of intercourse of the responders was one to three times per week.

On the other hand, the sexual position of the couples showed an obvious diversified tendency, which was aim at improving the quality of the sexual lives. Still, there is a tendency that more males than females convert sexual position. Men tend to be more interested in sex than women [26] and male-superior was the most dominant position in sexual intercourse [27]. This might be related to that young men would be more concerned with the quality and the quantity of their sex behavior. Women, on the other hand, are still socialized to be reluctant to express their sexual desires, and to be more hesitant about new or novel sexual behaviors than men. The differences might be associated with the continuing differences in gender role socialization and socially normative pressures.

Though there was no significant difference showed, but the frequency of men and women with higher education level was a bit lower than the counterpart with lower education level, which may be related to the corresponding jobs. Higher educators could own jobs with more psychological pressure and more busy lives, so they might have less sexual lives per month. However, they paid more attention on the quality of sexual lives, and changed positions more, and requiring more fresh feeling.

\subsection{Coordination with Sexual Partner}

The mutual caring and coordination is the basic condition of requiring satisfied sexual lives. Both of the couple had sexual requirement, not one alone. Both the coordination of male and female sexual partner was demanded to obtain a harmony sexual live.

Benuto L [28] reported that women endorsed more conservative attitudes than men, and Asian Americans had the most conservative sexual attitudes. Many women in China accepted the lives without the Puritanism and antisexual tradition of the Platonist and Judeo-Christian West [29], some of them were afraid of their sexual partner to look down upon themselves, and used sexual repression to show her dignity [30]. Moreover, in Confucianism and Taoism, sexual codes could have been intended to please the ruling class or for other manipulative political purposes [29]. And in the mind of most Chinese, a man is often the ruling class of the family. Therefore most women took sexual lives as a kind of moral obligation in marriage, and had a passive and negative attitude of sexual lives. These psychological factors became resistances of the exciting sexual practice. Besides, the physiological difference rendered female sexual arousal be more difficult than male. After kissing, foreplay etc. for a while to obtain sexual desire, male had become from excitement to loss of patience. Therefore, while male was exciting about sexual lives, female couldn't coordinated with male well. On the other way, the sexual desire of male is much stronger and the target organ was relatively more centralized. When their female partners had sexual requirement, they could easier to get motivated and coordinated with female partners.

\subsection{Self-Evaluation of Sexual Function}

In both sexes, sexual satisfaction and relationship satisfaction was positively associated with the self-evaluation of their sexual function. In this survey, much less female than male adults felt self-confident of their sexual function, and a few less female than male adults felt self-abase of their sexual function. This phenomenon might be caused by the difference of the living pressure of the female and male adults. In China, men were paid more attention as the leader of their lives and ruling class of the family, while women, in most cases, were taken as passive followers. Regarding to their sexual lives, men were expecting more satisfaction, which might also made them liable to the affection of interference, and easier to go to the other extreme. On the other hand, women lived relatively placid lives, and most of them took a general attitude of their sexual function. Also the education background didn't affect the self-evaluation of the female adults. Male adults with higher education background showed more confidence of their sexual function, and having more sexual satisfaction. 


\section{Limitations}

The analysis presented here suffered from several limitations. First, because of investigation staff and funding constraints, this study had to be designed to be a single community survey, not a national or urban populationbased, multi-center, random-sampled epidemiologic investigation. Second, there are some important issues of making love excluded through pilot testing and cognitive interview, such as anal sex, same-sex sexual intercourse, sexual partner fixed or not fixed or more, one-night stand, etc. The information of these issues is blank and needs to be further investigated. Third, this is only a descriptive study, and the related impact factors were not well taken into account. So, a national or urban population-based, multi-center investigation of how Chinese make love, including more issues of making love and the related impact factors, should be further designed and investigated in the future.

\section{Acknowledgements}

This study was sponsored partially by National Natural Sciences Foundation of China (No. 81070487 and 81370705).

\section{References}

[1] Yang, L., Li, X., Jin, T., Luo, L., Yuan, F., Fan, Y. and Xiong, Z.B. (2010) Study on the Current Status of Sexual Behaviors among the College Students in Chengdu. Chinese Journal of Family Planning, 172, 36-38.

[2] Deng, X.M. and Lin, J. (2009) Sexual Knowledge, Sexual Behavior and Double Standard Sexual Attitudes: Exploring Differences between Hongkong and Guangzhou University Students. China Journal of Health Psychology, 17, 145147.

[3] Peng, Y.H., Shen, L., Wo, J.Z., Xiang, Y.H., Li, E.X., Zou, G.X. and Liu, Y. (2009) Characteristics of and Relationship between Sexual Behavior, Sexual Attitude and Sexual Knowledge in College Students. Population Research, 133, 85-93.

[4] Liu, C.G., Zhou, C.H., Peng, Z.R. and Liu, X.Y. (2008) Investigation of College Students Sex Knowledge, Sex Attitude and Sex Behavior in Changsha City. Occupation and Health, 24, 1307-1308.

[5] Jin, C.C., Zou, H. and He, S.S. (2008) Situation and Relationship of College Students' Sexual Knowledge and Sexual Attitude. The Chinese Journal of Human Sexuality, 17, 10-14.

[6] Chen, B., Lu, Y.N., Wang, H.X., Ma, Q.L., Zhao, X.M., Guo, J.H., Hu, K., Wang, Y.X., Huang, Y.R. and Chen, P. (2008) Sexual and Reproductive Health Service Needs of University/College Students: Updates from a Survey in Shanghai, China. Asian Journal of Andrology, 10, 607-615. http://dx.doi.org/10.1111/j.1745-7262.2008.00413.x

[7] Xu, Q.Y., Feng, J.G., Li, L., Liu, X.H., Zhu, J.H. and Hu, M. (2007) Survey on Knowledge, Attitude and Practice about Sex among College Freshmen. Modern Preventive Medicine, 34, 1532-1533.

[8] Wu, J., Xiong, G.L. and Shi, S.H. (2007) Study on Sexual Knowledge, Attitudes and Behaviors of Adolescents. Chinese Journal of Child Health Care, 15, 120-124.

[9] Gon, L., Yan, C.R., Ding, R., Zhang, B.Y. and Peng, X.L. (2007) A Survey on Sex Psychology Development, Knowledge and Attitude among Shenzhen Middle School Students. Chinese Journal of Health Education, 23, $280-282$.

[10] Zeng, F.L., Yu, J. and Li, Z.H. (2006) Corresponding Analysis on Sexual Attitude of 1292 Adolescents in Guangzhou. Maternal and Child Health Care of China, 21, 660-662.

[11] Lori, A.B., Heather, M.C., Andrew, G.R., Boris, B.G. and Brooke, N.S. (2005) Acculturation and Sexual Function in Asian Women. Archives of Sexual Behavior, 34, 613-626. http://dx.doi.org/10.1007/s10508-005-7909-6

[12] Aniruddha, D., William, L.P. and Edward, O.L. (2009) Masturbation in Urban China. Archives of Sex Behavior, 38, 108-120. http://dx.doi.org/10.1007/s10508-007-9222-z

[13] Pinkerton, S.D., Bogart, L.M., Cecil, H. and Abramson, P.R. (2002) Factors Associated with Masturbation in a Collegiate Sample. Journal of Psychology and Human Sexuality, 14, 103-121. http://dx.doi.org/10.1300/J056v14n02_07

[14] Gerressu, M., Mercer, C.H., Graham, C.A., Wellings, K. and Johnson, A.M. (2008) Prevalence of Masturbation and Associated Factors in a British National Probability Survey. Archives of Sex Behavior, 37, 266-278. http://dx.doi.org/10.1007/s10508-006-9123-6

[15] Das, A. (2007) Masturbation in the United States. Journal of Sex \& Marital Therapy, 33, 301-317. http://dx.doi.org/10.1080/00926230701385514

[16] Kar, N. and Koola, M.M. (2007) A Pilot Survey of Sexual Functioning and Preferences in a Sample of EnglishSpeaking Adults from a Small South Indian Town. Journal of Sexual Medicine, 4, 1254-1261. 
http://dx.doi.org/10.1111/j.1743-6109.2007.00543.x

[17] Wang, R.J., Huang, Y. and Lin, Y.C. (2007) A Study of Masturbatory Knowledge and Attitudes and Related Factors among Taiwan Adolescents. Journal of Nursing Research, 15, 233-242. http://dx.doi.org/10.1097/01.JNR.0000387619.10554.f5

[18] Donnelly, D. and Straus, M. (1994) The Fusion of Sex and Violence. In: Straus, M.A., Eds., Beating the Devil Out of Them: Corporal Punishment in American Families, Lexington/MacMillan, Boston.

[19] Draycott, S. and Dabbs, A. (1998) Cognitive Dissonance. 1: An Overview of the Literature and Its Integration into Theory and Practice of Clinical Psychology. British Journal of Clinical Psychology, 37, 341-353. http://dx.doi.org/10.1111/j.2044-8260.1998.tb01390.x

[20] Durant, L.E., Carey, M.P. and Schroder, K.E.E. (2002) Effects of Anonymity, Gender, and Erotophilia on the Quality of Data Obtained from Self-Reports of Socially Sensitive Behaviors. Journal of Behavioral Medicine, 25, 439-467. http://dx.doi.org/10.1023/A:1020419023766

[21] Fisher, T.D. (2007) Sex of Experimenter and Social Norm Effects on Reports of Sexual Behavior in Young Men and Women. Archives of Sexual Behavior, 36, 89-100. http://dx.doi.org/10.1007/s10508-006-9094-7

[22] Wu, M.Q., Fan, L.J., Huang, J., et al. (2005) Investigation on the Style of Sexual Love Art of Married Women in Jiangmen. The Chinese Journal of Human Sexuality, 14, 4-6.

[23] Chivers, M.L., Seto, M.C. and Blanchard, R. (2007) Gender and Sexual Orientation Differences in Sexual Response to Sexual Activities versus Gender of Actors in Sexual Films. Journal of Personality and Social Psychology, 93, 11081121. http://dx.doi.org/10.1037/0022-3514.93.6.1108

[24] Uthman, O.A. (2008) Geographical Variations and Contextual Effects on Age of Initiation of Sexual Intercourse among Women in Nigeria: A Multilevel and Spatial Analysis. International Journal of Health Geographics, 30, 7-27.

[25] Seidman, S.N. and Rieder, R.O. (1994) A Review of Sexual Behavior in the United States. American Journal of Psychiatry, 151, 330-341.

[26] Buss, D.M. and Schmitt, D.P. (1993) Sexual Strategies Theory: An Evolutionary Perspective on Human Mating. Psychological Review, 100, 204-232. http://dx.doi.org/10.1037/0033-295X.100.2.204

[27] Tang, C.S., Lai, F.D. and Chung, T.K. (1997) Assessment of Sexual Functioning for Chinese College Students. Archives of Sexual Behavior, 21, 79-90.

[28] Benuto, L. and Meana, M. (2008) Acculturation and Sexuality: Investigating Gender Differences in Erotic Plasticity. The Journal of Sex Research, 45, 217-224. http://dx.doi.org/10.1080/00224490801987465

[29] Ng, M.L., Si, B. and Lau, M.P. (1990) Sexual Attitudes in the Chinese. Archives of Sexual Behavior, 19, 373-388. http://dx.doi.org/10.1007/BF01541932

[30] Guo, L.Y. and zhang, N. (2008) The Evolvement of the Female's Sexual Psychology and the Illumination. The Chinese Journal of Human Sexuality, 17, 3-6. 